Vol. 4, No. 1, Maret 2020, Hal. 93-100 e-ISSN2614-5758 | p-ISSN 2598-8158

crossref :https://doi.org/10.31764/jmm.v4i1.1781

\title{
LATIHAN BOOTCAMP MEMBANTU MENINGKATKAN KEBUGARAN KARYAWAN INDOFOOD
}

\author{
Mury Kuswari ${ }^{1^{*}}$, Nazhif Gifari ${ }^{2}$, Rachmanida Nuzrina ${ }^{3}$ \\ 1,2,3Prodi Gizi, Fakultas Ilmu-ilmu Kesehatan, Universitas Esa Unggul, Indonesia \\ 'mury@esaunggul.ac.id, ${ }^{1}$ nazhif.gifari@esaunggul.ac.id, ${ }^{3}$ rachmanida.nuzrina@esaunggul.ac.id
}

\begin{abstract}
ABSTRAK
Abstrak: Program latihan atau olahraga ditempat kerja merupakan salah satu kegiatan yang memiliki banyak manfaat terhadap kesehatan dan kebugaran karyawan. Produktivitas kerja dan menurunkan berbagai macam resiko penyakit tidak menular. Salah satu latihah yang popular dan cocok untuk karyawan adalah latihan Bootcamp. Kegiatan ini dilakukan pada karyawan Indofood sebanyak 70 orang. Bootcamp terdiri dari 10 pos yang dirancang untuk melatih seluruh anggota tubuh agar hasilnya lebih optimal. Seluruh karyawan sangat senang dan bersemangat mengikuti latihan Bootcamp ini karena gerakannya sangat mudah tetapi membutuhkan energi yang lumayan besar serta meningkatkan kebersamaan antar karyawan. Hasil pengabdian masyarakat ini diharapkan dapat meningkatkan kebugaran serta produktivitas karyawan dan dapat diaplikasikan pada berbagai perusaaan di Indonesia.
\end{abstract}

Kata Kunci: Latihan Bootcamp; Olahraga; Karyawan; Kebugaran.

\begin{abstract}
Workout or exercise programs at work are one of the activities that have many benefits to the health and fitness of employees. Work productivity and reduce various risks of non-communicable diseases. One of the most popular and suitable trainings for employees is Bootcamp training. This activity was carried out on 70 Indofood employees. Bootcamp consists of 10 posts designed to train all members of the body so that the results are more optimal. All employees are very happy and eager to take part in this Bootcamp training because the movements are very easy but require a considerable amount of energy and increase togetherness between employees. The results of community service are expected to improve employee fitness and productivity and can be applied to various companies in Indonesia.
\end{abstract}

Keywords: Bootcamp training; Exercise; Employee; Physical fitness

Article History:

Received: 03-02-2020

Revised : 26-02-2020

Accepted: 27-02-2020

Online : 04-03-2020

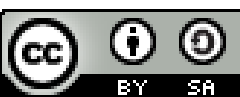

This is an open access article under the $C C-B Y-S A$ license 


\section{A. LATAR BELAKANG}

Gaya hidup yang ditandai dengan penurunan tingkat aktivitas fisik serta pola makan tinggi karbohidrat, tinggi lemak, rendah serat dan asupan energi yang berlebih merupakan penyebab terjadinya gizi lebih atau obesitas (Wiardani, 2016), (Hardiansyah \& Supariasah, 2017). Prevalensi gizi lebih di dunia yaitu 1,9 milyar atau $39 \%$ orang dewasa memiliki status gizi lebih dan 13\% diantaranya mengalami obesitas (WHO, 2016). Data Dinas Kesehatan RI (2013), melaporkan bahwa prevalensi obesitas pada kelompok umur dewasa sebesar $15.4 \%$ dan overweight sebesar 13.5\%, sedangkan di DKI Jakarta prevalensi kelebihan berat badan sebanyak $20 \%$.

Gizi lebih akan berdampak pada kesehatan tubuh misalnya mengalami penyakit degeneratif antara lain diabetes melitus, penyakit jantung koroner, stroke, hipertensi serta dapat menyebabkan kematian. Selain itu, seseorang dengan gizi lebih juga akan memiliki persen lemak tubuh yang tinggi (Achadi et al., 2010), (Putra, 2013).

Program kesehatan ditempat kerja diharapakan dapat mengurangi biaya kesehatan karyawan, meningkatkan produktivitas dan mengembalikan investasi positif perusahaan (Astrella, 2017). Tempat kerja menjadi tempat yang menjanjikan untuk program promosi kesehatan mengingat sebagian besar waktu dihabiskan ditempat kerja. Sebagaimana kita ketahui bahwa tempat kerja merupakan faktor sosial yang mempengaruhi terjadinya obesitas pada pekerja, sehingga tempat kerja menjadi sarana yang tpat untuk menjalankan program mengatasi obesitas (Cairns, Bambra, Hillier-Brown, Moore, \& Summerbell, 2015). Penelitian yang dilakukan pada karyawan dengan memberikan promosi kesehatan dapat meningkatkan tingkat aktivitas fisik dan juga kepatuhan untuk melakukan olahraga ditempat yang telah disediakan. Penelitian ini juga terbukti dapat meningkatkan meningkatkan kesehatan dan produktivitas kerja karyawan (Carr et al., 2016).

Saat ini lingkungan kerja dikantor mendorong para pekerja meningkatkan gaya hidup sedentary karena bekerja didepan meja sepanjang hari. Hal ini berkaitan erat dengan resiko terjadinya obesitas. Data World Health Organization (2011) menunjukkan estimasi sebanyak 3,2 juta orang meninggal setiap tahunnya karena perilaku sedentary atau kurang aktif dalam aktivitas fisik dan membuatnya menjadi penyebab kematian ke-4 di dunia. Oleh karena itu pekejaan menetap didepan computer atau meja dapat dikategorikan sebagai paparan berbahaya yang dapat meningkatkan resiko pekerja berbagai macam penyakit dan kematian dini (Carr et al., 2016).

Kelebihan berat badan ditandai dengan peningkatan lemak tubuh dan gangguan metabolisme yang berkontribusi dalam berbagai penyakit seperti; hipertensi, diabetes millitus, osteoarthritis dan berbagai penyakit lainnya (Donnelly et al., 2009). Lebih dari 1 miliyar orang dewasa di dunia kelebihan berat badan (Willumsen \& Bull, 2020). Olahraga merupakan salah satu upaya untuk mencegah dan mengatasi permasalahan obesitas karena berkontribusi pada peningkatan komposisi tubuh dan peningkatan pengeluaran energy.

Berbagai bentuk aktivitas fisik dapat dilakukan salah satunya yaitu latihan High Intensity Interval Training (HIIT). HIIT baru dikenalkan 
dalam beberapa tahun terakhir ini dan memiliki cara yang sangat efektif dan efisien untuk mencapai suatu tujuan seperti penurunan badan maupun komposisi tubuh seseorang. Beberapa study menunjukkan bahwa dengan melakukan HIIT selama 7 menit mampu merubah massa otot dan hal ini sebanding dengan melakukan jogging or biking selama satu jam. Keuntungan dari latihan HIIT ini adalah efektif dalam penurunan berat badan apalagi jika diimbangi dengan latihan dan memonitoring asupan makanan dan HIIT ini sangat efektif dari pada cara yang lain (Roy, 2013).

Berbagai penelitian mengenai latihan HIIT adalah latihan yang dilakukan dengan intensitas tinggi telah dilakukan selama mulai dari 8 minggu sampai 16 minggu yang mempunyai pengaruh terhadap komposisi tubuh. Latihan HIIT yang dilakukan pada 12 orang wanita obesitas selama 12 minggu untuk mengurangi lemak visceral abdomen, setelah diamati terjadinya penurunan persen lemak $(-2,5 \%,-2,4 \%)$, dalam pengurangan lemak visceral, HIIT merupakan salah satu strategi untuk mengendalikan obesitas dalam waktu singkat (Zhang et al., 2017).

Penelitian lainnya menunjukkan latihan HIIT merupakan latihan intensitas tinggi dimana dapat menekan pembakaran kalori yang lebih banyak dibandingkan dengan aktivitas fisik lainnya, khususnya setelah olahraga. Latihan HIIT yang secara alami sangat berat menyebabkan terjadinya Excess of Post Exercise Oxygen Consumption (EPOC) dan menekan lebih banyak hingga 6-15\% lebih kalori (energy expenditure) yang dikeluarkan selama latihan (Roy, 2013), (Bishop, Coombes, Le Gerche, \& Marsh, 2017).

Latihan HIIT signifikan terhadap penurunan lemak visceral diikuti dengan peningkatan volume latihan. Selama 15 minggu latihan HIIT dengan volume tinggi mampu menurunkan lebih besar lemak visceral (Heydari, Freund, \& Boutcher, 2012). Penurunan persen lemak dan lemak visceral tidak terlepas pola aktivitas fisik yang teratur, berolahraga dengan frekuensi 3-5 kali dalam seminggu efektif menurunkan persen lemak tubuh dan lemak visceral (Suresh, 2017). Penelitian Kuswari (2015) Kuswari (2015) menyatakan bahwa latihan aerobik dengan frekuensi 4 kali dalam seminggu dengan intensitas sedang mampu menurunkan lebak tubuh lebih besar dari pada frekuensi olahraga 2-3 kali.

Penelitian pernah dilakukan di tahun (1994) di Universitas Laval Kanada meyatakan bahwa HIIT dilakukan selama sembilan kali lebih efektif untuk penurunan lemak daripada steady-state cardio, seperti jogging. Hal ini dikarenakan HIIT akan membakar lemak tubuh kita selama kita latihan hingga dengan 48 jam setelah latihan. Penelitian lain juga menunjukkan bahwa latihan HIIT mampu menurunkan berat badan dengan menurunkan lemak dalam tubuh. Kondisi ini dikarenakan meningkatnya hormon testosterone dan hormon pertumbuhan (human growth) yang bertanggung jawab untuk meningkatkan lean mass dan menurunkan lemak. HIIT menstimulasi untuk memproduksi hormon pertumbuhan hingga 450 persen selama 24 jam dan setelah selesai berlatih. Hormon pertumbuhan bukan hanya bertanggung jawab untuk meningkatkan metabolisme dan fat-burning furnace juga memperlambat proses penuaan (Roy, 2013).

Sebuah meta-analysis yang dilakukan oleh Wewege, et al (2017) menyatakan bahwa dari 1,334 artikel kemudian di screening dan hanya 13 
artikel yang memenuhi kriteria dan penelitian menyebutkan rata-rata dengan latihan HIIT dan Moderate Intensity Continuous Training (MICT) selama 10 minggu sebanyak tiga kali seminggu sangat signifikan untuk menurunkan seluruh massa lemak tubuh dan lingkar pinggang. Penelitian lain menyebutkan bahwa HIIT yang dilakukan selama 12 minggu mampu menurunkan persentase lemak tubuh (Zhang et al., 2017).

Latihan HIIT dapat dilakukan dengan menggunakana jenis Bootcamp dengan memanfanfaatkan latihan berkelompok dan menggunakan berbagai peralatan sederhana seperti ban, tali tambang, barbels, cone dan alat lainnya. Latihan Bootcamp yang dilakukan bertujuan untuk membantu meningkatkan aktivitas fisik karyawan agar kebugaran semakin baik sehingga produktivitas karyawan semakin baik.

\section{B. METODE PELAKSANAAN}

Latihan Bootcamp karyawan Indofood ini dilakukan rutin 1 kali sebulan kepada seluruh karyawan agar mendapatkan kebugaran yang baik dan tubuh yang ideal sehingga meningkatkan produktivitas. Latihan ini dilaksanakan di lapangan parkir Indofood Tower Sudirman dan diikuti oleh 70 orang karyawan yang berasal dari berbagai unit dan devisi sehingga dapat meningkatkan kesadaran seluruh karyawan untuk rutin berolahraga. Pelaksanaan Bootcamp dimulai pukul 07.00 dan berakhir pada pukul 11.00. latihan dimulai dengan stretching selama 10 menit, dilanjutkan dengan latihan Bootcamp selama 40 menit dan dilanjutkan pendinginan selama 10 menit sehingga total pelaksanaan kegiatan 1 jam.

Bootcamp yang dilakukan terdiri dari 10 pos dengan berbagai kegiatan yang berbeda antara satu dan yang lainnya. Setiap pos dilakukan selama 3 menit dan dilanjutkan dengan istrahat 1 menit yang dipergunakan untuk berpindah antara pos satu dan pos yang lainnya sehingga total waktu yang dilakukan untuk menyelesaikan 10 pos adalah 40 menit. Gerakan setiap pos menyesuaikan dengan alat yang digunakan dalam acara ini yaitu ada dumbbells, ban traktor, ban mobil suv, tali tambang, karung pasir, matras, kettle belt dan berbagai alat fitness latinnya sehingga kegiatan tiap pos berbeda antara satu dan yang lainnya serta sangat bervariasi yang membuat kegiatan Bootcamp tidak monoton dan membosankan.

Selain kegiatan Bootcamp, kegiatan ini juga dibarengi dengan kegiatan pengukuran status gizi, konsultasi gizi, sesi talkshow kesehatan dan kebugaran serta adanya makan bersama. Enumerator dalam kegiatan ini dilakukan oleh para Nutrisionis Universitas Esa Unggul yang kompeten untuk dapat memberikan konsultasi gizi. Setelah kegiatan Bootcamp, seluruh peserta akan istirahat sambil makan yang sudah disiapkan kemudian sambil diberikan edukasi gizi kebugaran dengan tujuan untuk tetap mengedukasi akan pentingnya hidup sehat sehingga tubuh tetap bugar dan produktivitas meningkat. Materi diberikan dengan 4 bagian besar yaitu mengenai pentingnya mendapatkan tubuh ideal dan bahaya akibat kelebigan berat badan; dilanjutkan dengan makanan yang tepat dan sesuai untuk menunjang gaya hidup urban yang cepat dan dinamsi sehingga kebutuha gizi menjadi sangat penting dan harus tepat; dilajutkan dengan aktivitas fisik yang sesuai dan tepat untuk pekerja yang sibuk dan tidak memiliki banyak waktu untuk berolahraga di fitness center; dan yang terakhir adalah bagaimana menjaga pola hidup sehat yang sudah 
dilakukan tetap konsisten dilakukan agar tubuh menjadi sehat bugar dan produktif.

Setelah sesi edukasi kepada seluruh karyawan, kegiatan dilanjutkan dengan doorprize dan ramah tamah dengan seluruh karyawan untuk meningkatkan kebersamaan antar sesama karyawan serta meningkatkan semangat untuk saling memotivasi agar rutin berolahraga dan meningkatkan kebugaran. Di akhir sesi edukasi terdapat sesi tanya jawab kepada para peserta dan sharing pengalaman mengikuti kegiatan Bootcamp yang baru saja dilakukan.

\section{HASIL DAN PEMBAHASAN}

\section{Pelaksanaan Bootcamp}

Kegiatan dilaksanakan dengan penuh semangat dan antusias dari seluruh karyawan Indofood karena latihan Bootcamp merupakan latihan yang menyenangkan dan sangat bermanfaat meningkatkan kebugaran. Seluruh pos dapat dilewati oleh karyawan dengan sangat baik dan sesuai dengan aturan yang sudah diberikan sebelumnya. Latihan yang dilakukan secara berkelompok memiliki manfaat untuk saling memotivasi dan memperbaiki apabila kesalahan gerakan dilakukan oleh angota tim. Suasana pelaksanaan Bootcamp dapat dilihat pada Gambar 1 berikut.

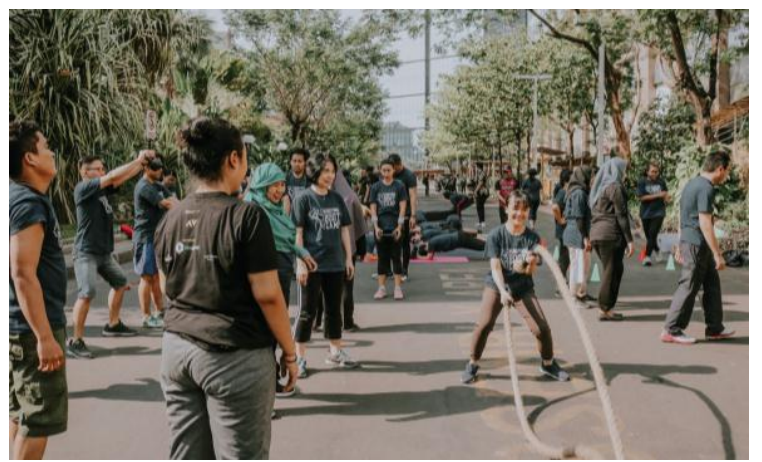

Gambar 1. Seluruh Karyawan Peserta Bootcamp

Setiap pos di dampingi oleh 1 orang trainer yang bertugas untuk memberikan contoh gerakan dan mengawasi gerakan selama pelaksanaan latihan agar gerakan yang dilakukan benar dan bermanfaat untuk kesehatan menjadi optimal. Pos yang paling seru dan paling banyak mendapatkan reposn positif dari seluruh peserta dalah pos mengangkat ban traktor dan memindahkannya dari satu titik ke titik lainnya. Suasana kegiatan ini terlihat pada Gambar 2.

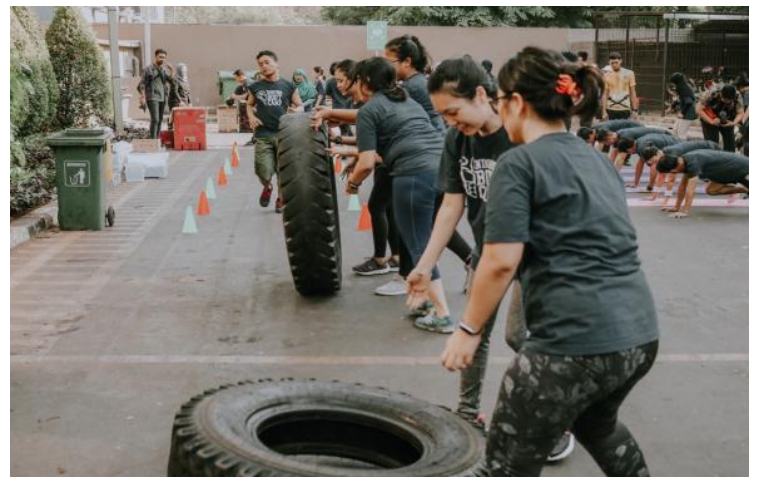

Gambar 2. Pos mengangkat dan memindahkan ban traktor 


\section{Kegiatan Edukasi Gizi}

Kegiatan edukasi gizi berlangsung di tengah-tengah arena Bootcamp sambil makan dan istrahat setelah melakukan latihan Bootcamp. Edukasi ini antusias diikuti seluruh peserta karena sangat banyak informasi baru yang didapat oleh peserta dan bisa diaplikasikan langsung dalam keseharian.

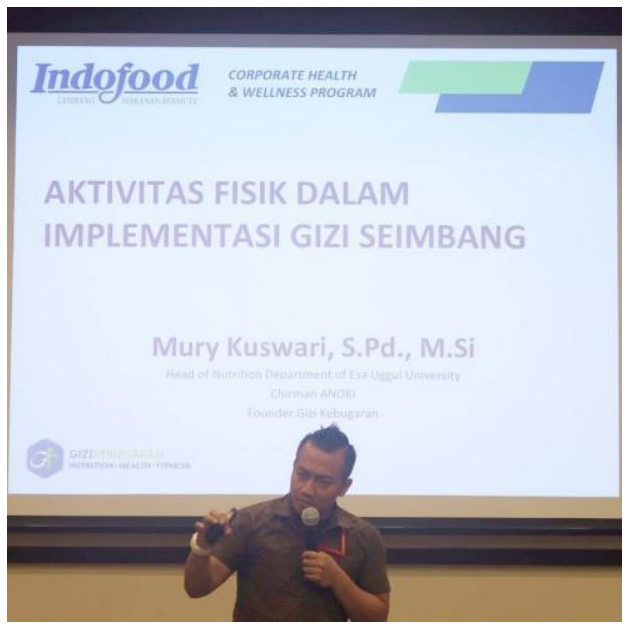

Gambar 3. Edukasi Gizi untuk karyawan

Gambar 3 di atas menunjukkan pemateri sedang menyampaikan materi tentang edukasi gizi yang merupakan salah satu cara untuk meningkatkan kesadaran kepada karyawan untuk tetap menjaga pola hidup sehat serta menjadi lebih produktif. Edukasi gizi yang diberikan disela-sela kegiatan Bootcamp dimaksudkan agar pesan kesehatan dengan rutin berolahraga dan menjaga pola makan yang baik dilakukan oleh seluruh karyawan.

Latihan Bootcamp dengan berbagai variasi gerakan yang tidak membosankan merupakan salah satu alternatif olahraga yang dapat dilakukan oleh karyawan karena waktu yang dilakukan tidak terlalu lama. Semakin banyak variasi gerakan dan gerakan menarik dapat membuat peserta bersemangat untuk mencoba dan menyelesaikan tantangan di tiap pos. Selain itu kegiatan Bootcamp yang dilaksanakan secara berkelompok ini dapat meningkatkan kebersamaan dan kekompakan antar karyawan berbagai untit yang dikelompokkan secara acak sehingga membuat saling kenal antar sesama karyawan dan meningkatkan produktivitas perusahaan.

\section{SIMPULAN DAN SARAN}

Latihan Bootcamp merupakan salah satu cara untuk meningkatkan kebugaran karyawan sehingga produktivitas karyawan akan semakin baik. Setiap tahun kegiatan yang dilakukan terus mengalami peningkatan pertisipasi dari peserta sampai 85\%. Harapannya partisipasi karyawan dapat terlaksana samakin baik dan diikuti seluruh karyawan. Selain itu juga edukasi gizi yang diberikan secara santai dan bersamaan dengan Bootcamp dapat menjadi salah satu cara edukasi yang baik kepada karyawan. Kegiatan ini terus berkembang dan menjadi contoh berbagai perusahaan lainnya di Indonesia untuk meningkatkan kebugaran dan produktivitas karyawan dengan latihan Bootcamp. 


\section{UCAPAN TERIMA KASIH}

Tim penulis mengucapkan terima kasih kepada PT. Indofood yang sudah memberikan kepercayaannya untuk menyelenggarakan kegiatan Bootcamp untuk seluruh karywan secara rutin setiap bulannya sehingga kegiatan ini menjadi salah satu agenda pengabdian rutin kami.

\section{DAFTAR RUJUKAN}

Achadi, E., Pujonarti, S. A., Sudiarti, T., Rahmawati, Kusharisupeni, Mardatillah, \& Putra, W. K. Y. (2010). Sekolah Dasar Pintu Masuk Perbaikan Pengetahuan, Sikap, dan Perilaku Gizi Seimbang Masyarakat. Jurnal Kesehatan Masyarakat Indonesia, 5(1), 42-47. https://doi.org/10.21109/KESMAS.V5I1.161

Astrella, J. A. (2017). Return on Investment: Evaluating the Evidence Regarding Financial Outcomes of Workplace Wellness Programs. Journal of Nursing Administration, $\quad 47(7-8)$, 379-383. https://doi.org/10.1097/NNA.0000000000000499

Bishop, D., Coombes, J., Le Gerche, A., \& Marsh, T. (2017). High intensity interval training symposium. Journal of Science and Medicine in Sport, 20, e3. https://doi.org/10.1016/j.jsams.2016.12.009

Cairns, J. M., Bambra, C., Hillier-Brown, F. C., Moore, H. J., \& Summerbell, C. D. (2015). Weighing up the evidence: A systematic review of the effectiveness of workplace interventions to tackle socio-economic inequalities in obesity. Journal of Public Health (United Kingdom), Vol. 37, pp. 659-670. https://doi.org/10.1093/pubmed/fdu077

Carr, L. J., Leonhard, C., Tucker, S., Fethke, N., Benzo, R., \& Gerr, F. (2016). Total Worker Health Intervention Increases Activity of Sedentary Workers. American Journal of Preventive Medicine, 50(1), 9-17. https://doi.org/10.1016/j.amepre.2015.06.022

Dinas Kesehatan Republik Indonesia. (2013). Riset Kesehatan Dasar. Diabetes Mellitus, 87-90. https://doi.org/1 Desember 2013

Donnelly, J. E., Blair, S. N., Jakicic, J. M., Manore, M. M., Rankin, J. W., \& Smith, B. K. (2009). Appropriate physical activity intervention strategies for weight loss and prevention of weight regain for adults. Medicine and Science in Sports and Exercise, Vol. 41, pp. 459-471. https://doi.org/10.1249/MSS.0b013e3181949333

Hardiansyah, \& Supariasah, I. D. (2017). Ilmu Gizi Teori dan Aplikasi. In Gizi Bayi dan Balita.

Heydari, M., Freund, J., \& Boutcher, S. H. (2012). The effect of high-intensity intermittent exercise on body composition of overweight young males. Journal of Obesity, 2012. https://doi.org/10.1155/2012/480467

Kuswari, M., Setiawan, B., \& Rimbawan. (2015). Frekuensi Senam Aerobik Intensitas Sedang Berpengaruh Terhadap Lemak Tubuh Pada Mahasiswi Ipb. (2015). Jurnal Gizi Dan Pangan, 10(1). https://doi.org/10.25182/jgp.2015.10.1.

Putra, S. R. (2013). Pengantar Ilmu Gizi dan Diet. Yogyakarta: D-Medika.

Roy, B. A. (2013). High-Intensity Interval Training. ACSM'S Health \& Fitness Journal, 17(3), 3. https://doi.org/10.1249/fit.0b013e31828cb21c

Suresh, N., \& Reddy, R. L. (2017). Effect of Lifestyle on Body Fat Percentage and Visceral Fat in Indian Women with Above Normal Body Mass Index. (2017). International Journal of Current Research and Review. https://doi.org/10.7324/ijcrr.2017.9195

Wewege, M., van den Berg, R., Ward, R. E., \& Keech, A. (2017). The effects of highintensity interval training vs. moderate-intensity continuous training on body composition in overweight and obese adults: a systematic review and metaanalysis. Obesity Reviews, Vol. 18, pp. 635-646. 
https://doi.org/10.1111/obr.12532

Wiardani, N. K. (2016). Ilmu Gizi Teori dan Aplikasi. Jakarta: Buku Kedokteran.

Willumsen, J., \& Bull, F. (2020). Development of WHO guidelines on physical activity, sedentary behavior, and sleep for children less than 5 years of age. Journal of Physical Activity and Health, 17(1), 96-100. https://doi.org/10.1123/jpah.2019-0457

World Health Organization (WHO). (2011). The Global Prevalence of Anaemia in 2011 WHO Library Cataloguing-in-Publication Data. The Global Prevalence of Anaemia in. https://doi.org/10.1111/j.1600-0854.2007.00534.x

Zhang, H., Tong, T. K., Qiu, W., Zhang, X., Zhou, S., Liu, Y., \& He, Y. (2017). Comparable Effects of High-Intensity Interval Training and Prolonged Continuous Exercise Training on Abdominal Visceral Fat Reduction in Obese Young Women. Journal of Diabetes Research, 2017. https://doi.org/10.1155/2017/5071740 